\title{
Some effects of wavelength discrimination on stimulus generalization in the goldfish'
}

\author{
LAWRENCE L. AMES AND MATTHEW YARCZOWER
}

UNIVERSITY OF MARYLAND

\section{Abstract}

Five goldfish were trained to strike a key illuminated with $550 \mathrm{~m} \mu$ to obtain food on a VI $30 \mathrm{~min}$. schedule. After 30 days of single-stimulus training the Ss were divided into two groups: one group remained on singlestimulus training while the other group was given discrimination training. The discrimination training consisted of $\mathrm{S}+(550 \mathrm{~m} \mu)$ trials randomly alternated with S- $(590 \mathrm{~m} \mu)$ trials which were not reinforced. After 15 days of training the Ss were tested for generalization in extinction using 9 different wavelengths. The Ss were then retrained so that each $\mathrm{S}$ who previously had single-stimulus training now received discrimination training and vice versa. After 17 days of retraining the Ss were retested for generalization. Behavioral contrast and peak-shifts were found with the goldfish. In addition, the effects of both discrimination training and the obtained stimulus generalization gradients appeared to be reversible with the goldfish.

\section{Introduction}

Much of the recent work on the effects of discrimination training on generalization gradients has used pigeons as experimental Ss and visual wavelength as the stimulus dimension (Blough \& Millward, 1965). The present study was an attempt to extend the range of this experimentation to the goldfish. It has already been suggested that the wavelength discriminability function for the goldfish is quite similar to that of the pigeon (Yarczower \& Bitterman, 1965).

Procedure

The Ss were five goldfish (Carassius auratus) about 4 in long obtained from a fish hatchery near Frederick, Maryland.

The apparatus consisted of a darkened enclosure of black Plexiglas
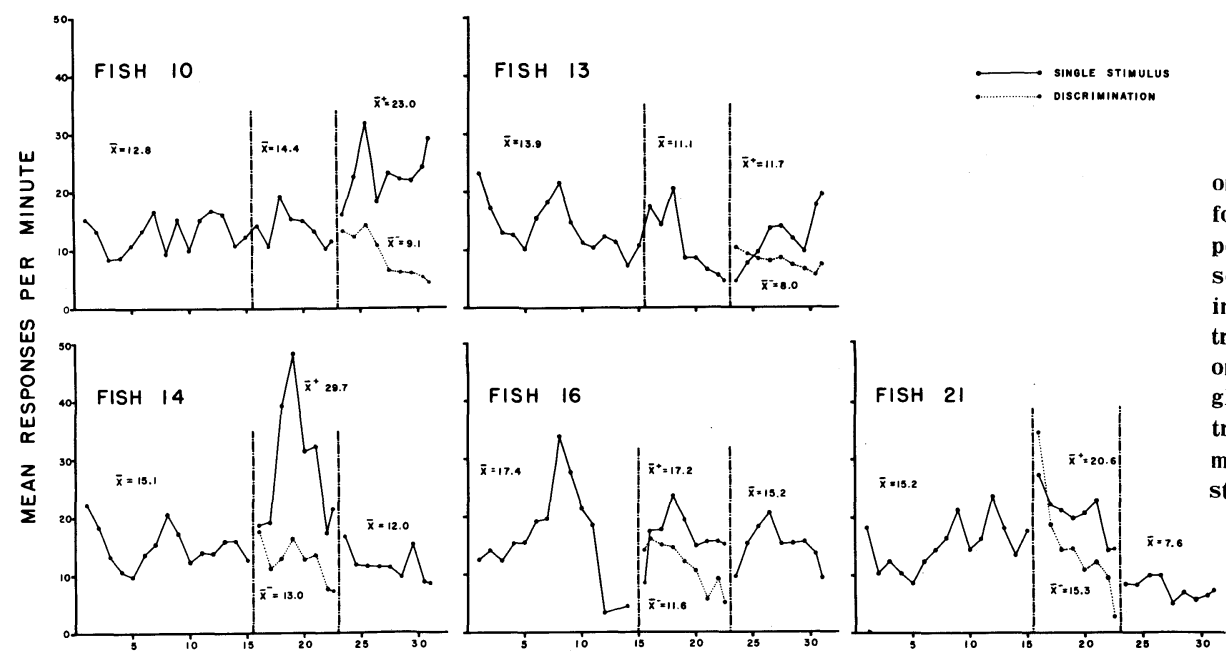

BLOCKS OF TWO EXPERIMENTAL DAYS to which each fish was brought in its individual 2-gal aquarium; a light source and monochromator, a feeder, and associated control and recording equipment. The response key was a $3 / 4$ in by 2 in piece of translucent milk Plexiglas which was mounted $1 / 2$ in below the surface of the water. The response was detected by a photoelectric system. Food reinforcements (BiOrell) were brushed automatically into a feeding ring located slightly above the key. Further details of the apparatus can be obtained by writing to the authors.

The fish were first magazine trained, shaped to hit the response key and were then given 20 reinforcements on a continuous reinforcement schedule (CRF). The fish were then placed on a mixed schedule in which two schedules of reinforcement were alternated with no stimulus change from one schedule to the other (Ferster \& Skinner, 1957). The Ss received one day under each of the following schedules: mix CRF-FR 2; mix CRF-FR 3; mix CRF-FR 5. The Ss were subsequently given two days at mix FR 5-VI $30 \mathrm{~min}$. and then were placed on a VI $30 \mathrm{~min}$. schedule for the remainder of training.

Single-stimulus training

Single-stimulus training consisted of $201 \mathrm{~min}$. presentations of S+ $(550 \mathrm{~m} \mu$ ) during which they were reinforced on a VI $30 \mathrm{~min}$. schedule of reinforcement. Each stimulus presentation was separated by 10 sec. during which the stimulus light was off and reinforcements were never administered. The Ss were run on single-stimulus training for 30 days at which time the Ss were divided into two groups of three and two fish. The group of two Ss subsequently received 10 singlestimulus trials per day for 15 days. The group of three fish was given discrimination training.

Discrimination training

Discrimination training consisted of 10 trials of S+ $(550 \mathrm{~m} \mu)$ randomly alternated with 10 trials of S- $\left(590 \mathrm{~m}_{\mu}\right)$. A VI $30 \mathrm{~min}$. schedule of reinforcement was in effect during S+ and extinction was in effect during S- periods. The discrimination Ss were run for 15 days at which time all showed a statistically significant $(p<.05)$ difference (Wilcoxon's unpaired replicates test) in responding to the two stimuli.

\section{Generalization tests}

All Ss were tested in a single test session. The Ss who had been given single-stimulus training were given two reinforced trials in
Fig. 1. The mean response rates on the training schedule are shown for each fish in blocks of two experimental days. The vertical lines separate the three stages of training for each $S$ : single stimulus training for all Ss; single-stimulus or discrimination training; and single-stimulus or discrimination retraining. Generalization tests were made after the second and third stages of training. 


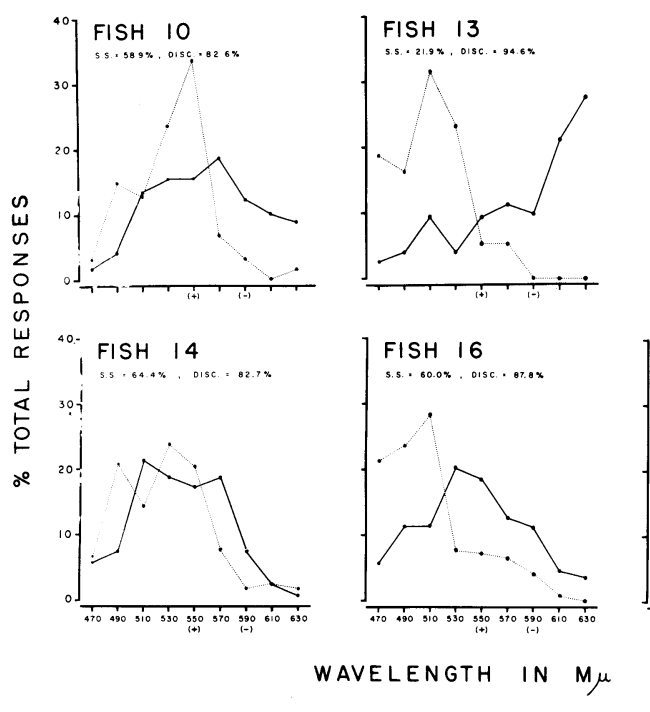

the presence of $550 \mathrm{~m} \mu$ preceding generalization testing, while those Ss who had been given discrimination training received two reinforced trials in the presence of S+ alternated with two trials of extinction in the presence of S-. The 9 test stimuli were then presented in 5 randomized sets for a total of 45 test trials. The generalization test trials were $30 \mathrm{sec}$. in duration and were not reinforced. Retraining and refesting

All Ss were given 17 days of retraining and were tested again using the same procedure as the first test. The three Ss who had received discrimination training were now given single-stimulus training, and the two Ss who had received single-stimulus training were now given discrimination training.

\section{Results and Discussion}

Figure 1 shows the results of the three stages of training: (1) single-stimulus training for all Ss; (2) single-stimulus or discrimination training; (3) discrimination or single-stimulus retraining. The general effect of discrimination training appeared to be an initial increase in rate in the presence of both S+ and Swith a subsequent decrease in S-. Fish 10, 14 and 21 appear to show positive contrast (Reynolds, 1961) while fish 13 and 16 do not. Fish 10 indicates that the contrast effect was a function of the discrimination training procedure and not of reducing the number of reinforced trials per session in half.

Generalization tests were conducted after the second and third stages of training. The results of these tests are shown in Fig. 2.2 The percentage of responses in the presence of wavelengths shorter than the training stimulus are recorded for each S. Fish 10 and 13 received in order, (1) single-stimulus training, (2) generalization test, (3) discrimination retraining and (4) generalization retest. Fish 14, 16, and 21 received in order, (1) single-stimulus training, (2) discrimination training, (3) generalization test, (4) single-stimulus retraining and (5) generalization retest. One effect of the discrimination training procedure on the generalization gradient was to increase the percentage of responses in the presence of wavelengths shorter than the training stimulus. Fish 13, 14 and 21 also show a peak-shift in the generalization gradient obtained after discrimina-
Fig. 2. The percent total responses made in the generalization test is shown for each $S$ as a function of the 9 test stimuli.. Each $S$ was tested for stimulus generalization following both single-stimulus and discrimination training. The percent total responses made to wavelengths shorter than (but not including) the training stimulus is indicated for each $\mathbf{S}$ following both single-stimulus and discrimination training. tion training although the magnitude of the shift does not appear to be correlated with the amount of behavioral contrast.

Thus the effects of wavelength discrimination training using goldfish as Ss appear to produce effects similar to those reported with pigeons. That is, the discrimination training procedure produced a rate increase in the presence of $\mathrm{S}+$ in some $\mathrm{Ss}$, and also produced a peak-shift in some of the subsequently obtained generalization gradients.

The present experiment also suggests that the effects of discrimination training are reversible in the goldfish. Fish 14 and 16 who had been trained on discrimination training and then retrained on singlestimulus training produced gradients similar to singlestimulus training when retested. The importance of demonstrating reversible effects of discrimination training is that the same subject may then be used in generalization experiments to evaluate both the effects of single-stimulus and discrimination training.

\section{References}

Blough, D. S., \& Millward, R. B. Operant conditioning and verbal learning. In P. R. Farnsworth (Ed.), Annual review of psychology. Palo Alto: Ann. Rev., 1965. Pp. 63-94.

Ferster, C. B., \& Skinner, B. F. Schedules of reinforcement. New York: Appleton-Century-Crofts, 1957.

Reynolds, G. S. Behavioral contrast. J. exp. Anal. Behav., 1961, $4,57-72$.

Yarczower, M., \& Bitterman, M. E. Stimulus generalization in the goldfish. In D. I. Mostofsky (Ed.), Stimulus generalization. Stanford, Calif.: Stanford University Press, 1965. Pp. 179-192.

\section{Notes}

1. This research was supported in part by NASA Traineeship ZOWT09 to the first-named author and in part by Grant MH08819-01 from the National Institutes of Mental Health to the second-named author. We are indebted to Dr. M.. L. Wolbarsht of the Naval Medical Research Institute Bethesda, Maryland, who made available some of the optical equipment. Reprints may be obtained from M. Yarczower, Department of Psychology, University of Maryland, College Park, Maryland.

2. Due to an error fish 21 was given $20 \mathrm{~min}$. of extinction in Sthree days before the first generalization test. 